\title{
Hemostasis and Hemotherapy
}

\author{
Wolfgang Korte ${ }^{a}$ Marco Cattaneo ${ }^{b}$ \\ ${ }^{a}$ Center for Laboratory Medicine; and Hemostasis and Hemophilia Center St. Gallen, Switzerland; \\ bUnità di Medicina III, ASST Santi Paolo e Carlo, Dipartimento di Scienze della Salute, Università degli Studi di Milano, Milan, Italy
}

The current issue of Transfusion Medicine and HemoTHERAPY is dedicated to various hemostasis aspects that will influence hemotherapy in one way or the other. We believe that this is timely, as hemostasis management has made its way from a highly specialized topic worked upon by a relative small group of expert care givers and technicians to a topic that is widely recognized to have increasingly broad and major clinical impact, dealt with by an increasingly less specialized group of users. Thus, this area nowadays receives increasingly broad attention. The fascination of hemostasis management, however, is unbroken. In order to provide optimal patient care, it is of utmost importance to continuously expand our knowledge on physiology, pathophysiology, optimal usage of technical equipment, therapeutic products, and treatment processes.

The articles of this special topic attempt to give insights into different aspects of various parts of modern hemostasis pathophysiology and hemostasis management; they might be considered representative for various aspects of hemostasis (management) and thus might be helpful in various hemotherapeutic treatment decisions.

The discussion of potential thromboembolism in patients with inherited fibrinogen disorders is an example of a (potentially serious) side effect in hypocoagulable patients, where the use of procoagulant treatment options might lead to clinically relevant hypercoagulability [1].
Peri-interventional hemostasis is an increasingly important area of research. However, only scarce knowledge on the relationship between thromboelastometry or thromboelastography and conventional parameters of hemostasis exists [2]. Thus, it is important to research such relationships; new research presented here shows that factor XIII, alone and in combination with other parameters, has a frequent and profound effect on postoperative clot firmness [3].

Early intervention (and therefore fast to immediate availability of procoagulant products) is an important mainstay to avoid the vicious cycle of perioperative coagulopathy; this is the very practical reason why the experiments for fast thawing devices reported here are important [4].

'New' (NOACs) or 'direct' oral anticoagulants (DOACs) are continuing to seize their increasing share of indications for antithrombotic therapy. As these patients will also be in increasing need for surgery or other interventions, reliable point-of-care testing to exclude or suggest the presence of NOACs (or DOACs) in the peri-interventional setting is therefore a requirement; such a methodology is reported for the one oral thrombin inhibitor on the market [5].

Overall, hemostasis issues in various facets are becoming increasingly important in current medical practice, especially in patients that might develop a need for hemotherapy. This is why we believe that this issue is of special interest for a diversified audience.

\section{References}

1 Korte W, Poon M-C, Iorio A, Makris M: Thrombosis in inherited fibrinogen disorders. Transfus Med Hemother 2017;44: DOI: 10.1159/000452864

2 Adler M, Ivic S, Bodmer NS, ten Cate H, Bachmann LM, Wuillemin WA, Nagler M: Thromboelastometry and thrombelastography analysis under normal physiological conditions - systematic review. Transfus Med Hemother 2017;44: DOI: 10.1159/000464297.
3 von Rappard S, Hinnen C, Lussmann R, Rechsteiner M, Korte W: Factor XIII deficiency and thrombocytopenia are frequent modulators of postoperative clot firmness in a surgical intensive care unit. Transfus Med Hemother 2017;44: DOI: 10.1159/000468946.

4 Heger A, Pock K, Römisch J: Thawing of pooled, solvent/detergent-treated plasma octaplasLG ${ }^{\circledR}$ : validation studies using different thawing devices. Transfus Med Hemother 2017;44: DOI: 10.1159/000460302.
5 Körber MK, Langer E, Köhr M, Wernecke K-D, Korte W, von Heymann C: In vitro and ex vivo measurement of prophylactic dabigatran concentrations with a new ecarin-based thromboelastometry test. Transfus Med Hemother 2017;44: DOI: 10.1159/000470622.

\section{KARGER}

() 2017 S. Karger GmbH, Freiburg

Fax +497614520714 